\title{
USE OF CD-ROMIS IN SPANISH LIBRARIES
}

\author{
David I. Raitt": Ching-chih Chen"
}

\begin{abstract}
A study was carried out in public, academic, special and government libraries and information centres in Western Europe during 1989 on the use of CD-ROMs and optical products. Following a brief account of the background to the survey, the paper analyses the results in more depth for libraries and information centres in Spain and compares these results where relevant with the overall total European response as well as those from individual countries. It is evident that optical products in general and CD-ROMs in particular are not yet in widespread use in libraries.

Keywords: CD-ROM, optical products, Spanish libraries, Spain.

Resumen: Se llevó a cabo un estudio acerca de la utilización del CD-ROM en las bibliotecas públicas, académicas y centros de documentación de los países de Europa Occidental durante 1989. Se analizan con más detenimiento los resultados obtenidos en bibliotecas espaniolas, comparándolas con el resto de Europa, llegándose a la conclusión de que los productos ópticos en general, y el CD-ROM en particular no se emplean habitualmente en las bibliotecas españolas.

Palabras Clave: CD-ROM, discos ópticos, bibliotecas españolas, España.
\end{abstract}

\section{Introduction}

A survey on the use of CD-ROMs and other optical products in public, special, academic, government and other types of libraries as well as information and documentation centres in eighteen Western European countries was carried out during the first nine months of 1989. The study was carried out under the auspices of FID (Fédération Internationale d'Information et de Documentation) with partial funding from the CEC (Commission of the European Communities - DGXIIIB) for the twelve countries of the European Economic Community. For completeness, Austria and Switzerland were also included in the survey and NORDINFO, who were sponsoring a similar survey in the five Nordic countries, agreed to use the same questionnaire for Finland, Iceland, Norway and Sweden and distribute it in Denmark on behalf of FID.

The latest ( 9 th) edition of the Saur World Guide to Libraries was used as the primary source for obtaining the names and addresses of the European libraries. Initial distribution of questionnaires started in week 4 of 1989 for the Nordic countries and week 10 for most of the other countries and was completed by week 25 for Spain. In an attempt to maximize the return from Spain the questionnaire and covering letter were translated into Spanish. Most of the returned questionnaires from Spain were completed in Spanish. Preliminary and more detailed results of the European survey have been presented elsewhere $(1,2,3)$.

\footnotetext{
Erlitor, The Electronic Library; ${ }^{*}$ Graduate School of Library and Information Science, Simmons College, Boston, USA

Recibido 23-1-90
} 


\section{Analysis of Spanish library returns}

\subsection{Use of optical products in Spanish libraries}

Table 1 gives a breakdown of the number of questionnaires mailed out to all libraries and subsequently returned. As can be seen, out of a total of 13.568 questionnaires distributed to libraries and information centres throughout Europe, 1304 were mailed to Spanish libraries (ie almost 10\% of the total and one of the highest amounts) and of these $240(18 \%)$ were returned. This compares to $7 \%$ for Italy (the lowest) and $64 \%$ for Denmark (the highest - after a follow-up). Since the total return from all eighteen countries was 3130 , the Spanish returns represent $8 \%$ of the total return - and account for $10 \%$ of the responses from EEC countries.

Table 1

Detailed Country Breakdown of Number of Questionnaires Mailed and Returned

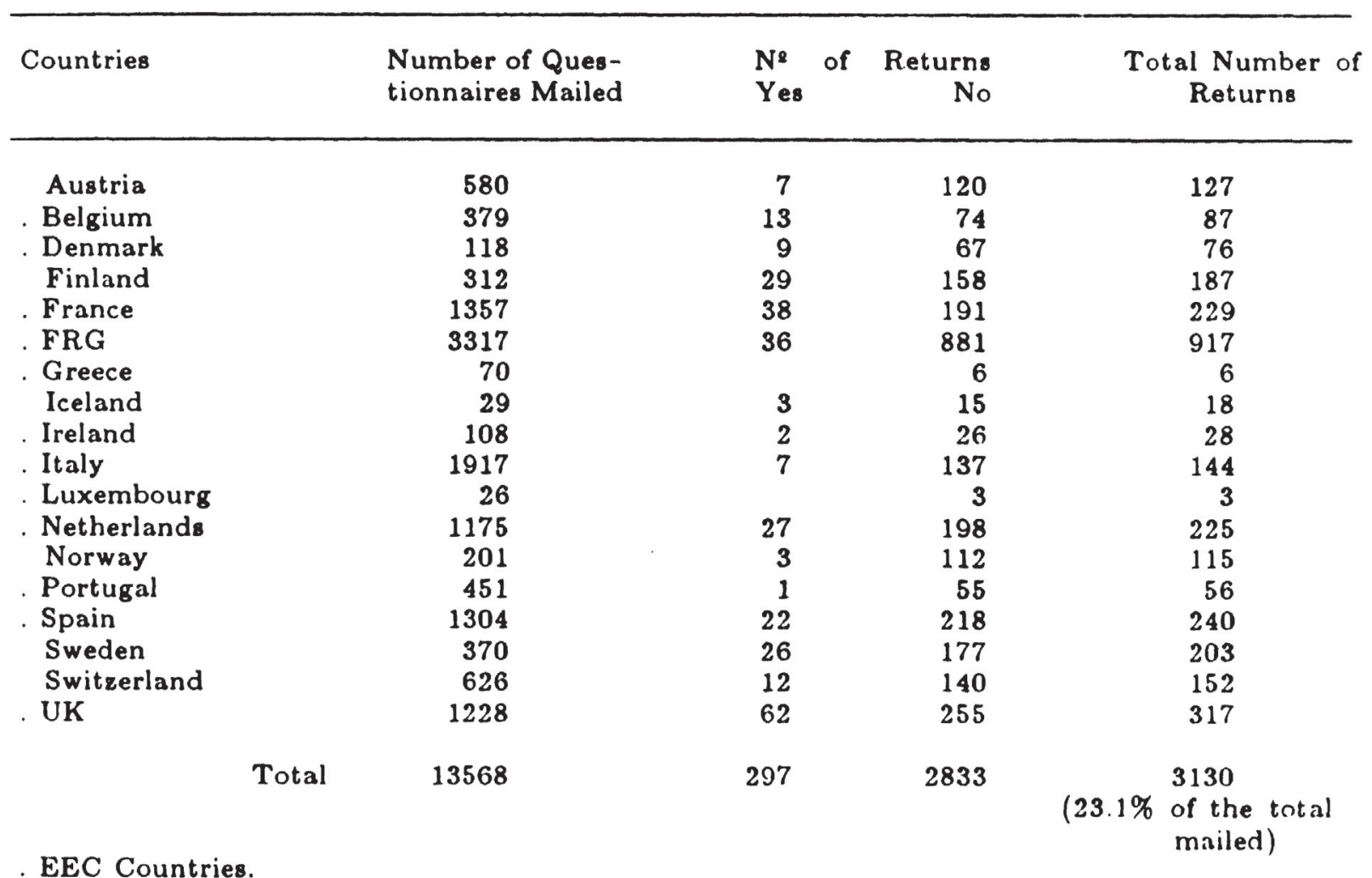

EEC Countries.

Of those 240 questionnaires returned by Spanish libraries only $22(9 \%$ responded they were already actually using optical products (and these were exclusively CD-ROMs). This was in the middle of the range of responses reported - higher than Italy $(5 \%)$ and West Germany $(4 \%)$ as well as several others, but lower than the $20 \%$ of Bristish libraries who reported they $u \rightarrow r e$ using optical products (Fig. 1). In other words, $91 \%$ of the Spanish libraries which replied were not yet using either CD-ROMs, videodisks or other forms of optical disks and presumably the picture is much worse since one could 
perhaps assume that those who did not return the questionnaire (which was in Spanish) were not using optical products either.

Figure 1

Optical Product Acquisition in European Libraries

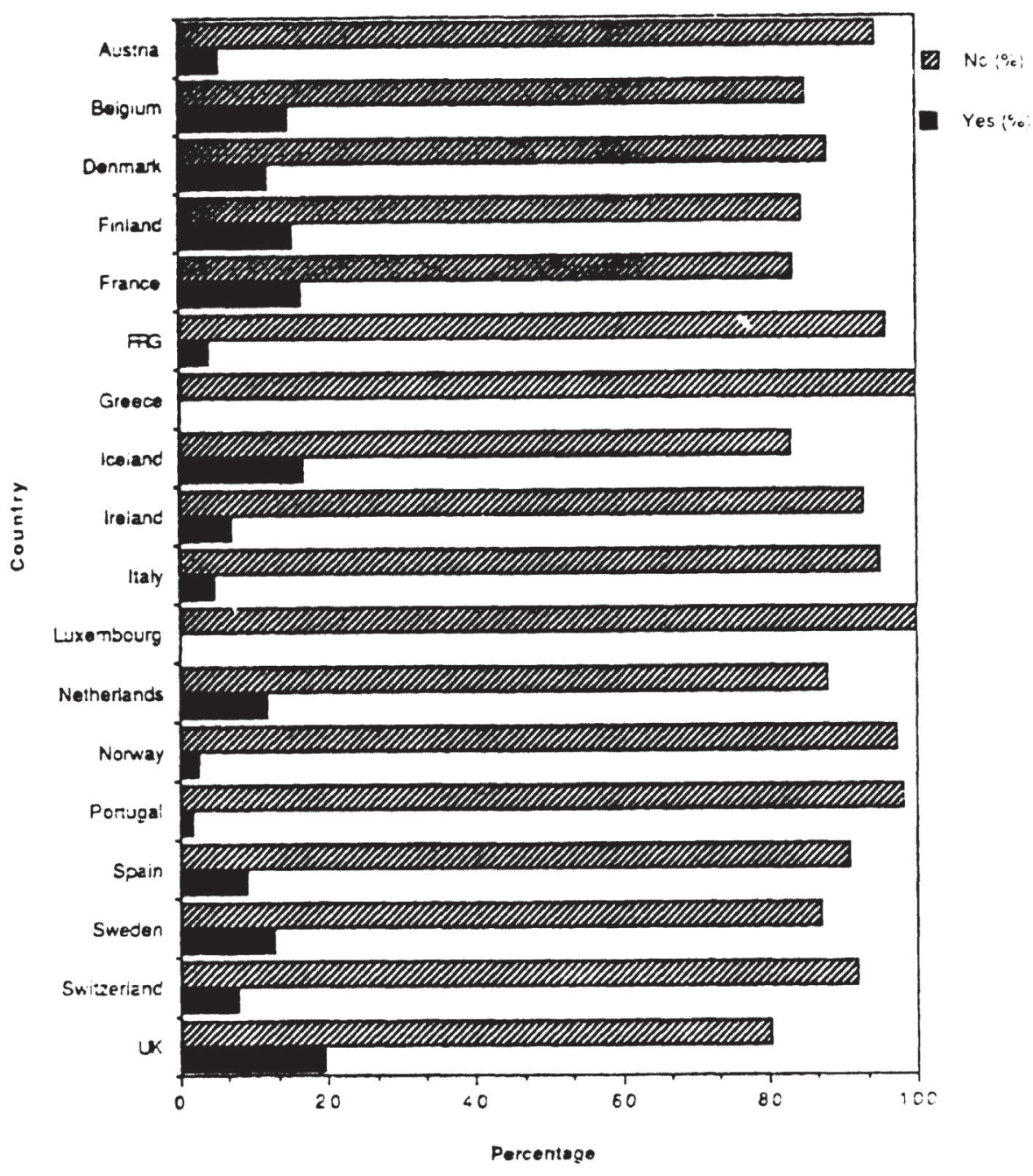

The 22 Spanish positive replies (ie those using CD-ROMs) actually represent $7 \%$ of the total positive replies (297 from all countries - 9,5\% of the total European return) and this is the seventh highest total comparing to $12 \%$ for West Germany, 13\% for France and $21 \%$ for the United Kingdom which gave the highest positive returns. If just EEC countries are considered then the Spanish positive replies account for $10 \%$ of the total positive replies compared to almost 17\% for West German, 18\% for French and $29 \%$ for UK libraries. By comparison Finnish libraries using optical products account for $41 \%$ of the total positive replies from the five Nordic countries.

The breakdown by type of library for the 22 Spanish libraries replyingthey were using CD-ROMs is academic libraries (17), special (3) and government 
(2) - no public libraries replied they had acquired CD-ROMs. Regarding the 218 libraries replying that they were not yet using CD-ROMs, the figures are: academic libraries (101), special (78), government (25) and public (14). Barcelona was the city with the highest number of CD-ROM users (7), followed by 4 in Madrid and 1 in each of another eleven cities. Conversely, the highest number of negative replies (ie those not using CD-ROMs) came from libraries in Madrid (53), Barcelona (33), Zaragoza (7) and Murcia (7). A further 24 cities had between 2 and 5 libraries responding to the questionnaire - but by far the vast majority of cities had only one library which responded.

Fully $80 \%$ of the libraries in Spain replying that they had not yet installed CD-ROMs had under 50.000 volumes in their collection and almost $90 \%$ had less than 100.000 volumes. $88 \%$ had less than ten staff - in many instances it was only one - and $44 \%$ had less than 1000 users. These figures compare unfavourably with the rest of Europe - where around $50 \%$ of all libraries replying had under 50.000 volumes, $74 \%$ had less than ten staff and $50 \%$ had under 1000 users.

\subsection{Acquisition of CD-ROM products}

While the actual range of CD-ROM products taken by Spanish libraries was from 1 to $8,68 \%$ of those responding that they took CD-ROMs had only one product - this compares to $42 \%$ for Europe as a whole. Six libraries took between two and four products and one took eight. The total number of products (not necessarily unique) taken by the responding Spanish libraries was 39. Most of the products had been bought by the libraries responding, although a few indicated they were leased or obtained for review or test purposes.

The most popular CD-ROM taken by library and information centres in Europe as a whole was MEDLINE in all its versions, which was taken by a quarter of all those responding. Books in Print was next, taken by $20 \%$; while the BL/BN Pilot disc, BookBank, ERIC (all versions) and Ulrich Plus were taken by over $10 \%$. In Spain the picture was somewhat different - Medline was the most popular CD-ROM and used by over half the libraries. This was followed, a long way behind, by Bibliofile and the Serials Directory. Next were Ulrich Plus and Compuley - each acquired by almost $10 \%$ of libraries.

Asked if they would be willing to pay for other optical products, a good proportion of libraries in Spain said that, based on their experience with the products they had already bought, they would be prepared to buy new products - particularly if they were in the Spanish language. Reasons for buying (given that money was available) included that products were useful and provided better access to information and were more efficient to search.

\subsection{Impact of optical products}

Nearly one fifth of Spanish libraries $(18 \%)$ indicated they had not had optical products long enough to be able to ascertain their impact on isers. Where this information was available, there had been a generally favourable and positive impact. Specific observations were that CD-ROMs enabled greater information access (noted by $32 \%$ ), saved the users time $(23 \%)$ and 
enabled a faster service (23\%). Nearly half the respondents noted they would cancel subscriptions to printed abstract journals not so much to save money or space but because they did not need both print and optical versions - and the CD-ROM version was preferred. On the other hand a number of libraries said they still needec paper access.

Virtually no respondents had actually integrated optical products into their in-house operations and very few libraries and information centres were considering implementing an optical publishing project of their own at the present time. It was generally felt that CD-ROMs offered the highest potential for fast, end-user retrieval of bibliographic references and/or full-text documents in the form of encyclopaedias and directories.

Severat of the respondents who replied they did use CD-ROMs noted that their usage of online databases was reduced. The main reason given for reduced online use was that $C D$ - $R O M$ s were cheaper and were always available for searching and in fact could be searched without any accompanying telecommunication difficulties. This meant that end-users could do searches themselves without the necessity of an intermediary.

Out of a total of 493 CD-ROM players in European libraries, $28(6 \%)$ were installed in libraries in Spain. Although one Spanish library possessed four and another three, the majority of libraries $(81 \%)$ in the country had only one drive. Hitachi drives - in 50\% of the libraries replying - seemed to be the most popular CD-ROM player in Spain. Philips drives were used in nearly one third of Spanish libraries, while the remaining libraries used Amdex, Sony and Toshiba drives. The CD-ROM installations were normally used by library staff rather than end-users.

\subsection{Pros and cons of CD-ROM products}

On the whole users found many CD-ROMs easier, faster, more flexible and more convenient to use than corresponding print and online products. Many CD-ROMs were considered better than print products and were of ten more comprehensive in coverage. They also offered more powerful search capabilities and interaction and end-users could search them without the necessity of an intermediary. Since there were no telecommunication links and thus no line failures and breakdowns - and because there was no apparent cost to search (ie no per minute or hit charge) there was less time/cost pressure and stress on the searcher.

On the other hand, some users found certain CD-ROM software somewhat inflexible and difficult to use and they preferred the flexibility and layouts of online databases. A number of libraries complained that CD-ROMs could only be used by one person at a time and were slower to search than online databases - certainly for quick reference or browsing or single look-ups. Other criticisms were the limited amount of data, missing relevant sources and the short time-span covered by some CD-ROMs as well as the fact that they were not updated frequently enough.

Some twelve different features and facilities were listed by Spanish respondents as being desirable for CD-ROMs. Among the most requested were more frequent updating; more user friendliness; and a standardized search language. Other features requested by libraries in other European countries included faster response time; cheaper products with a better price structure 
(ie no leasing); networking, remote and multi-user access; better printing capabilities; and better help facilities and menus. More coverage of all types of material (eg books, encyclopaedias, directories etc) was also required as was better coverage of chemistry, business and law.

\subsection{Libraries intending to acquire CD-ROMs}

218 libraries in Spain said they were not currently using optical products. Asked if they were thinking of acquiring them, 71 (33\%) replied that they would probably acquire them in a year or two, while $143(66 \%)$ said they would not acquire them and $1 \%$ said they might.

Many libraries did not reply to the questions asking why they would or would not install CD-ROMs and what factors were likely to influence their decision. For those that did reply reasons for wanting to acquire CD-ROMs included that the library would be able to offer better services to users $(6 \%$ said this - compared to $12 \%$ for Portugal and $16 \%$ for the UK) as well as provide faster access to more information (also mentioned by $6 \%$ ). Another $6 \%$ thought that it was time to get them because they were popular now and considered hi-tech - this compares to $11 \%$ for Sweden. Others believed they would offer the potential for more efficient searches and a few wanted to get them to save space.

Regarding factors which would influence the decision whether to acquire optical products or not, $25 \%$ of Spanish libraries said it depended on the cost of products and/or on whether they were able to get the necessary budget to pay for them. This is slightly higher than the response from the total European return which was $22 \%$ - but much less than the UK and Denmark where $57 \%$ and $56 \%$ of libraries said it depended on the cost and/or the budget. 19\% said their decision rested on the type and variety of product that became available on CD-ROM and their ease of use and time-saving. A fair number mentioned they were dependant on decisions from higher authorities and quite a few, particularly universities, were involved in amalgamation or network plans.

As for products required, it was quite obvious that many more products of a Spanish character were desired. This was, in fact, the same for most other European countries, ie countries wanted optical products in their own native languages and relating to material of a local or national nature. The most requested products by those relatively few Spanish libraries replying were ERIC and Medline.

\subsection{Libraries not intending to acquire CD-ROMs}

Those not intending to acquire optical products stated it was because they were just too expensive or they had no budget or funds available or that they could not justify the cost $(11 \%)$. A relatively small number of respondents $(8 \%)$ indicated they simply had no need for such products or that there was inadequate demand for them - this compares to $25 \%$ of Danish libraries and $20 \%$ of British libraries. Others considered there were insufficient suitable products available to meet their users' needs. While $8 \%$ of Spanish libraries considered they were too small to install CD-ROMs or were not automated, some 18\% of Italian libraries, 17\% of Swiss and 16\% of Belgian 
that their libraries were too small or specialized or lacked suitable staff and sufficient space.

\section{Conclusion}

This paper has provided a brief summary of the results of a survey into the use of optical products in all types of Spanish library and information centres. The survey revealed that, as of Autumn 1989, relatively few libraries in Spain as well as in the rest of Europe are currently using optical products. Where they are being used, they are mainly CD-ROMs and in many cases they have been acquired only very recently and thus libraries have not yet had much opportunity to evaluate either their impact or their advantages and disadvantages. It is clear that, at present, CD-ROMs are being used mainly in the larger academic libraries which have large book stocks, large staffs and a large user community. They are also being used mainly by library staff for library purposes such as bibliographic verification, orders and acquisitions, cataloguing and indexing. The survey also showed up a relatively suprising lack of knowledge and awareness about the availability, applications and use of CD-ROMs and optical products in general. It is hoped to carry out a further study in a year or so and it will in be interesting to compare the picture then with now.

\section{References}

1. Raitt, D.I.; Chen, Ching-chih. Optical products in European libraries and information centres: results of a survey. In: Proceedings of the International Online Information Meeting, 13th. 1989, Dec 12-14, London, England. Learned Information, 1989. p227-232

2. Raitt, D.I.; Chen, Ching-chih. Use of optical products in libraries and information centres in Western Europe. THE Electronic Library, 8 (1), 1990.

3. Chen, Ching-chih; Raitt, D.I. Survey on the use of optical information products in libraries and information centres in Europe. FID, 1990. FID, 1990. FID Publication 683. 